\title{
Elucidating novel mechanisms of brain injury following subarachnoid hemorrhage: an emerging role for neuroproteomics
}

\author{
Melanie D. King, B.S., Melissa D. Laird, M.S., Sangeetha Sukumari Ramesh, Ph.D., \\ Patrick Youssef, M.D., Basheer Shakir, M.D., John R. Vender, M.D., \\ Cargill H. Alleyne Jr., M.D., and Krishnan M. Dhandapani, Ph.D. \\ Department of Neurosurgery, Medical College of Georgia, Augusta, Georgia
}

Subarachnoid hemorrhage (SAH) is a devastating neurological injury associated with significant patient morbidity and death. Since the first demonstration of cerebral vasospasm nearly 60 years ago, the preponderance of research has focused on strategies to limit arterial narrowing and delayed cerebral ischemia following SAH. However, recent clinical and preclinical data indicate a functional dissociation between cerebral vasospasm and neurological outcome, signaling the need for a paradigm shift in the study of brain injury following SAH. Early brain injury may contribute to poor outcome and early death following SAH. However, elucidation of the complex cellular mechanisms underlying early brain injury remains a major challenge. The advent of modern neuroproteomics has rapidly advanced scientific discovery by allowing proteome-wide screening in an objective, nonbiased manner, providing novel mechanisms of brain physiology and injury. In the context of neurosurgery, proteomic analysis of patientderived CSF will permit the identification of biomarkers and/or novel drug targets that may not be intuitively linked with any particular disease. In the present report, the authors discuss the utility of neuroproteomics with a focus on the roles for this technology in understanding SAH. The authors also provide data from our laboratory that identifies high-mobility group box protein-1 as a potential biomarker of neurological outcome following SAH in humans. (DOI: 10.3171/2009.10.FOCUS09223)

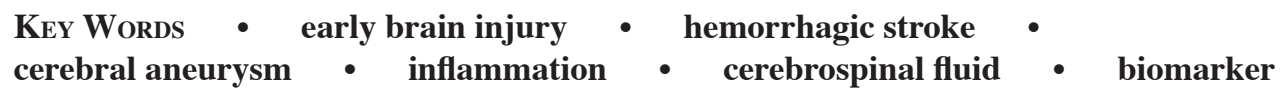

$\mathrm{N}$ EuROLOGICAL injuries are associated with longterm disability and significant patient death. Aside from a significant emotional toll, brain injuries place a massive economic burden on society each year. Despite decades of intense investigation, clinical treatment options remain limited, in part, due to the poorly defined sequelae underlying injury progression. The cellular pathways culminating in neurological demise are likely activated within the first minutes to hours following the injury, suggesting that early diagnosis and intervention may be paramount to improving patient prognosis.

The identification of clinically viable therapeutics to limit brain injury remains a subject of intense research focus. Over the past several decades, preclinical research proceeded in a logical, hypothesis-driven manner in which the involvement of a single gene or protein was tested for a given biological function based on existing

Abbreviations used in this paper: $\mathrm{BBB}=$ blood-brain barrier; $\mathrm{HMGB}=$ high-mobility group box protein; $\mathrm{IL}=$ interleukin; $\mathrm{NPH}=$ normal-pressure hydrocephalus; $\mathrm{NVU}=$ neurovascular unit; $\mathrm{SAH}=$ subarachnoid hemorrhage; TLR $=$ toll-like receptor. reports in the literature. Unfortunately, despite great promise in preclinical trials, species differences, drug delivery issues, and poor brain penetration contributed to the inability of most experimental drugs to significantly improve patient outcomes following brain injury. Thus, the incorporation of innovative research strategies may be required to further elucidate the mechanisms of brain injury at the molecular and cellular levels and provide novel targets for improved drug design.

In contrast to the systematic and laborious task of investigating the role of 1 established gene at a time, the advent of genomic and proteomic approaches allows the simultaneous, large-scale screening of all gene/proteins in a biological sample. These advanced screening techniques also allow objective, nonbiased data collection, permitting the identification of biomarkers and/or novel drug targets that may not be intuitively linked with any disease process. These findings may then be exploited in further preclinical and clinical testing. Although these technologies are often criticized as nonhypothesis driven, genomic and proteomic screening methods have significantly increased the mechanistic understanding of 
numerous physiological and pathological processes and aided in the identification of disease biomarkers.

We believe that the field of neurosurgery stands to greatly benefit from these rapidly evolving technologies, both in the diagnosis (biomarker discovery) and therapeutic intervention (target discovery, validation, and novel drug design) of complex neurovascular pathologies. To maintain focus, the potential applicability of advanced genomics/proteomics will be discussed in the context of $\mathrm{SAH}$, a type of hemorrhagic stroke caused by the spontaneous rupture of a cerebral aneurysm. Original data from our research group, demonstrating the utility of proteomic screening of patient specimens in novel drug target and biomarker identification, will also be provided.

\section{Therapeutic Targeting Following SAH: Many Questions, Few Answers}

Subarachnoid hemorrhage remains a major cause of death and disability in the US, with a prevalence of 1 in 10,000 people (approximately 7\% of all strokes). ${ }^{29,61} \mathrm{Al}-$ though the overall incidence of stroke declined over the past several decades, the frequency of SAH remains stable despite medical advancements. ${ }^{111}$ Patients with SAH exhibit a 30-day mortality rate of $30-40 \%$ and sustain a loss of productive life years comparable to that of patients with cerebral infarction, due in part to the young age of onset, dearth of viable therapeutic options, and poor clinical prognosis. ${ }^{29,38,62,64}$ The estimated lifetime cost per SAH patient is double that of a patient with ischemic stroke, as $\sim 50 \%$ of patients with SAH experience permanent disability (such as deficits in verbal and nonverbal memory, psychomotor speed, executive function, and visual-spatial function). ${ }^{21,39,45,56,64}$ Overall, $\sim 70 \%$ of patients with SAH die or require long-term assisted care due to neurological impairments.

The dogmatic view of SAH suggests that delayed cerebral vasospasm, a progressive narrowing of the large cerebral arteries $\sim 4-10$ days postictus, is the primary cause of neurological demise and death following $\mathrm{SAH}$. Based on the clinical correlation between the onset of cerebral vasospasm and neurological deterioration, intense research efforts were focused on limiting large artery constriction with the hope that this would improve patient outcome. Unfortunately, a recent clinical trial showed that clazosentan, an endothelin receptor antagonist, successfully reduced angiographic vasospasm by $\sim 65 \%$ without a corresponding improvement in neurological function or 3-month patient outcome.$^{40}$ Consistent with this finding, preclinical data from our laboratory and others indicated a similar functional dissociation between cerebral vasospasm and neurological outcome. ${ }^{74,114}$ Together, these unexpected findings challenge the view that delayed cerebral vasospasm is solely responsible for brain injury following SAH and suggest that a reevaluation of the disease process may be required..$^{40,72,74,84,114}$ Although a detailed assessment of the state of the field is beyond the scope of this report, the reader is directed to several excellent commentaries on the current challenges associated with managing SAH. ${ }^{40,70,84}$
Early Brain Injury as a Cause of Subsequent Neurological Demise?

Early brain injury, a group of detrimental neurovascular pathologies that occur in the acute injury phase following $\mathrm{SAH}$, includes cortical spreading depression, neuroinflammation, microvascular injury, BBB opening, and global cerebral edema. ${ }^{6,16,21,22,25,26,55,58,68,69,97,101,113,119}$ Although the initiating events in the cause of early brain injury remain unclear, changes within the NVU are implicated in neurological demise following SAH. ${ }^{82,123-125}$ The NVU is composed of neurons, glia, and microvessels organized into discreet units, each of which may communicate with and influence the physiology of the other cell types. For example, astrocytes are in juxtaposition to both neurons and endothelial cells and functionally influence the formation and maintenance of the $\mathrm{BBB},{ }^{1,47,56}$ regulation of cerebral blood flow in response to neuronal activity, ${ }^{46,59,103}$ maintenance of oxidative balance, ${ }^{56}$ promotion of synaptogenesis, and neuroprotection. . $^{1,83,108,109,114}$ Thus, perturbations within the NVU may negatively impact brain function after SAH. Along these lines, a vasoconstrictive response generated within minutes of SAH reduced cerebral blood flow and initiated a damaging cascade of events, including enhanced ischemic brain injury and early death, following experimental and clinical SAH. ${ }^{9,12,56,89,91,114,118}$

\section{Understanding Neurological Injury After SAH: Where Do We Go From Here?}

Whereas novel avenues of exploration into the mechanisms underlying neurological demise (beyond cerebral vasospasm) are clearly needed, the lack of a focused research direction presents a major obstacle in the field. Although there is growing appreciation for the role of early brain injury in determining neurological outcome following $\mathrm{SAH}$, elucidating the complex cellular interactions within the NVU presents unique and technically challenging issues. As such, the traditional research model involving the development of a hypothesis centered upon a single gene/protein in disease progression followed by resource (time, labor, and cost)-intensive experimentation may not provide adequate mechanistic information in a timely manner. Thus, new experimental approaches and tools will be needed to fully understand the pathogenesis of brain injury following SAH. In the following sections, the potential utility of neurogenomics and neuroproteomics to identify and define the molecular and cellular changes within the NVU following SAH are discussed.

\section{The Genomic Revolution}

The information gained by the sequencing of the human genome permits the integration of gene expression, gene mutations, epigenetic modifications, and gene polymorphisms (single nucleotide polymorphisms) with biological/functional outcomes, opening an exciting new era in translational research., ${ }^{2,56}$ Microarray ("gene chip") analyses permit the large-scale, simultaneous comparison of gene expression between 2 or more study populations (such as healthy control patients vs those with disease), 
allowing the identification of individual genes or patterns of gene expression, including those not previously linked with a given disease process. This information may provide novel mechanisms of disease phenotype/progression and/or identify correlations between DNA polymorphisms and disease risk, such as the risk of developing a cerebral aneurysm.

Gene expression profiling technology identified 138 differentially expressed genes within the large cerebral arteries following SAH in rats, providing potential mechanisms of delayed cerebral vasospasm and neurological demise. ${ }^{112}$ Of these changes, a known function was ascribed to 77 genes using the Online Mendelian Inheritance in Man (OMIM) database (http://www.ncbi.nlm. nih.gov/omim/), which houses genetic information on human disorders and diseases, including a large number implicated in processes related to inflammation, metabolism, oxidative stress, and regulation of the extracellular matrix. A similar study reported the upregulation of 18 genes associated with inflammation and cellular injury within vasospastic cerebral arteries following SAH in dogs ${ }^{77}$ suggesting a possible role for inflammatory mediators following the rupture of a cerebral aneurysm.

Inflammation may signal an adaptive response to promote tissue repair, ${ }^{23,43}$ but uncontrolled or chronic inflammation, such as that observed during Alzheimer disease, Parkinson disease, and ischemic brain injury, irreversibly damages tissue and promotes oxidative stress. ${ }^{44,60,66,67,76,80}$ Mechanistic studies to support the functional validity of the preclinical microarray data remain largely unexplored; however, initial clinical observations and preclinical data from our laboratory and others suggest that antiinflammatory compounds attenuate acute brain injury following SAH. ${ }^{48,56,73,85,114,116}$ For example, mice overexpressing the gene for extracellular superoxide dismutase or copper-zinc superoxide dismutase exhibited a reduction in the development of cerebral vasospasm and attenuation of oxidative stress. ${ }^{49,72,92}$ Similarly, CSF or serum from patients with SAH exhibited more immune complexes, complement activation, and increased levels of oxidative and inflammatory mediators (such as IL-6, tumor necrosis factor- $\alpha$, and intercellular adhesion molecule-1) as compared with control patients. ${ }^{20,32,34,42,50,56,87,90,101}$ These preliminary findings indicate the utility of microarray analysis for advancing the mechanistic understanding of acute brain injury following SAH and provide potential therapeutic targets for future preclinical and clinical studies.

Genomic studies after SAH in humans remain completely unexplored, in part due to the ethical and technical issues associated with the collection of tissue samples from patients with $\mathrm{SAH}$. Whereas preclinical models of hemorrhagic stroke provide abundant access to mRNA, brain tissue from patients with $\mathrm{SAH}$ is not readily available. In contrast, blood is readily obtained from patients during routine clinical care, allowing blood genomic expression profiling. Although unreported following $\mathrm{SAH}$, microarray analysis using peripheral blood mononuclear cells collected from patients with cerebral ischemia revealed an increase in the expression of hypoxia-induced stress genes, vascular repair genes, and neuroprotective genes, as compared with blood collected from control pa- tients. Although these types of studies potentially provide unique clinical insights into the pathophysiology of brain injury, it remains unclear whether blood genomic responses accurately reflect the brain response to injury (for example, whether immune cells exhibit the identical genomic response as neurons following hypoxia-ischemia). Similarly, it is unknown whether the observed changes in peripheral blood cells indicate specific responses to the injury or whether these changes actually reflect other preexisting conditions within individual patients, such as vascular disease, hypertension, and diabetes. ${ }^{7,28}$

Together these findings suggest that the methods of sample collection and data analysis must be carefully considered when interpreting the findings from these types of studies. Additionally, mRNA expression is dynamic and varies from minute to minute, requiring the ability to repeatedly collect living cells over time. Finally, changes in mRNA expression are a relatively poor predictor of protein expression and biological activity. ${ }^{37}$ Thus, while genomics provides an important foundation for identifying novel therapeutic targets, these important caveats may diminish the utility of gene expression following $\mathrm{SAH}$ in humans. As such, changes in protein expression and/or modification may provide more meaningful information regarding the complex mechanisms underlying neurological injury following SAH. In the following section, we discuss the potential applicability of proteomics in the study of brain injury.

\section{Proteomics: the Next Step on the Journey}

The complement of proteins within a cell or tissue (called the proteome) is considerably larger and more complex than the human genome. For example, alternative splicing of a single transcript may result in several different isoforms of a protein, significantly increasing the number and diversity of proteins. Further complicating the analysis of proteins following brain injury, posttranslational protein modifications such as phosphorylation, glycosylation, and myristoylation modulate protein activation states and protein-protein interactions, providing additional complexity. Thus, advanced technologies are needed to identify the key mediators of neurovascular injury. Once identified, preclinical modeling studies, such as those that use transgenic mice that lack or overexpress a molecule of interest, may be used to define whether a given protein is protective, detrimental, or both. In this section, we highlight the potential utility of proteomic analyses following brain injury. This is followed by the presentation of data from our laboratory, demonstrating the use of proteomic screening in patient-derived CSF to identify a possible biomarker/cellular mechanism of brain injury following $\mathrm{SAH}$.

Proteomics, a method of emerging clinical importance, permits a direct comparison of protein expression between 2 or more populations (controls vs patients with disease). A major benefit of proteomic research is that novel proteins may be discovered and linked with a disease process for the first time, without the need for an existing hypothesis or precedent for that particular protein in the given disease process. To accomplish this goal, 
samples of interest are resolved by 2D gel electrophoresis, a method that separates complex protein mixtures by charge, then by molecular weight, ${ }^{18}$ resulting in the generation of a 2D gel electrophoresis map and a reference map of all proteins in a given sample. By comparing the spot location for an individual protein between 2 populations, changes in protein expression may be determined. Spots that show distinct differences between experimental groups can then be analyzed by techniques such as liquid chromatography-tandem mass spectrometry, which combines 1 or more chromatographic steps with 2 rounds of mass spectrometry ${ }^{74}$ This procedure allows the identification of individual proteins within complex, heterogeneous biological samples, including serum and CSF.

\section{Proteomic Subdivisions}

Bayés and $\mathrm{Grant}^{8}{ }^{8}$ classified proteomics into 4 distinct subdivisions. The first subdivision, expression neuroproteomics, involves the qualitative and quantitative profiling of the proteome and is traditionally accomplished using gel electrophoresis. ${ }^{78}$ The second subdivision, functional neuroproteomics, studies the functional properties of individual proteins, including posttranslational modifications and organization of proteins into substructures, complexes, and networks. Data obtained using this method has improved the understanding of complex biological systems, such as the molecular organization of postsynaptic density, which would not otherwise be possible with genomic analyses. ${ }^{94}$ For example, many proteins involved in the presynaptic apparatus ${ }^{14,102}$ and the postsynaptic anchoring and clustering of $N$-methylD-aspartate-type glutamate receptors were identified using this method. ${ }^{27,33,52,59,63,75}$

Clinical neuroproteomics, the third subdivision, focuses on drug discovery and on the identification of novel biomarkers and disease mechanisms for neurological, neurodegenerative, and psychiatric diseases. ${ }^{17,41,105,110,115,117}$ In particular, CSF provides an increasingly important resource for identifying novel changes within the brain. The final subdivision, neuroproteomic informatics, addresses the computation tools and databases necessary for handling and analyzing complex proteomic data sets. These technologies are important for determining statistically meaningful data and for the establishment of databases and repositories for proteomic data, which may be mined at a later date by other investigators. In the context of neurosurgery, we believe that clinical neuroproteomics may be particularly useful for identifying novel biomarkers of disease (in controls vs patients with disease) and/or providing novel cellular targets for future drug discovery. As such, the remainder of this review will focus on the potential applicability of this subcategory of neuroproteomics following SAH.

\section{Cerebrospinal Fluid: A Gateway to the Brain?}

Human brain specimens are not readily obtainable from patients with SAH, but CSF diversion is routinely performed in the neurointensive care unit, providing an easily accessible source of proteins from patients. Cerebrospinal fluid circulates throughout the brain and con- tains high amounts of protein $(\sim 15-40 \mathrm{mg} / \mathrm{dl}),{ }^{30}$ making this the sample of choice for novel biomarker discovery using proteomic methodologies. Proteomic screening of CSF was first performed nearly 4 decades ago to provide novel insights into human brain physiology and disease. ${ }^{24,31,51}$ Initial studies performed in 1980 using 2D gel electrophoresis revealed $\sim 300$ proteins in human CSF, although most of these proteins remained unidentified at this time ${ }^{35}$ Subsequent studies in the early 1990 s, using improved technologies, detected $\sim 1000$ proteins of which 248 were identified. ${ }^{121}$ More recent studies in 2007 using liquid chromatography-tandem mass spectrometry revealed the presence of $\sim 2500$ proteins, ${ }^{80,81}$ providing essential information to generate an atlas of the human CSF proteome, a valuable resource that provides a potential source of brain disease biomarkers. ${ }^{81}$ Given the availability of patient CSF within an academic medical center, our research group attempted to identify novel biomarkers of neurological injury following SAH, which may aid in the early diagnosis and treatment of these patients. These original data are presented in the following section.

\section{High-Mobility Group Box Protein-1: A Predictive Biomarker of Neurological Outcome Following SAH?}

Using proteomic screening technologies, we detected the expression of a $25 \mathrm{kD}$ protein, HMGB1, in the CSF of all 9 of the patients with SAH who we analyzed. In contrast, HMGB1 was below the level of detection in the CSF of all 7 control patients (Fig. 1), suggesting HMGB1 release may be specific to brain injury. Notably, the levels of HMGB1 within the CSF retrospectively correlated $(\mathrm{r}=$ 0.786 ) with neurological outcome, as determined by the Hunt and Hess grading scale (Fig. 2A), and were highly correlated $(r=0.938)$ with the degree of disability or dependence at patient follow-up examinations, as assessed by the modified Rankin scale (Fig. 2C). In contrast, the HMGB1 content of CSF was not strongly correlated ( $\mathrm{r}$ $=0.334)$ with the appearance of SAH on CT scans, as determined by the Fisher grade (Fig. 2B). Together, these novel data implicate HMGB1 as a possible biomarker for neurological injury and as a predictive marker of patient outcome following SAH. These findings also provide a rationale for characterizing the functional role of HMGB1 in promoting brain injury after SAH.

High-mobility group box protein-1, also called HMG or amphoterin, is an evolutionarily conserved, nonhistone DNA binding protein that is constitutively expressed in most cells throughout the body, including the brain..$^{57,106}$ Under physiological conditions, HMGB1 localizes to the nucleus to stabilize nucleosomal structure and to facilitate gene transcription..$^{15}$ In contrast, HMGB1 functions as a proinflammatory cytokine when translocated into the extracellular space. ${ }^{3,4,19,36,56,105}$ Thus, HMGB1 may be classified as an "alarmin," a multifunctional host protein that activates an immune response to warn neighboring cells of injury. ${ }^{10,99}$ Consistent with this assertion, HMGB1 is increased in the CSF in patients with meningitis ${ }^{105}$ and in the serum of patients with cerebral ischemia, ${ }^{36}$ suggesting HMGB1 may represent a marker of neurological injury. 

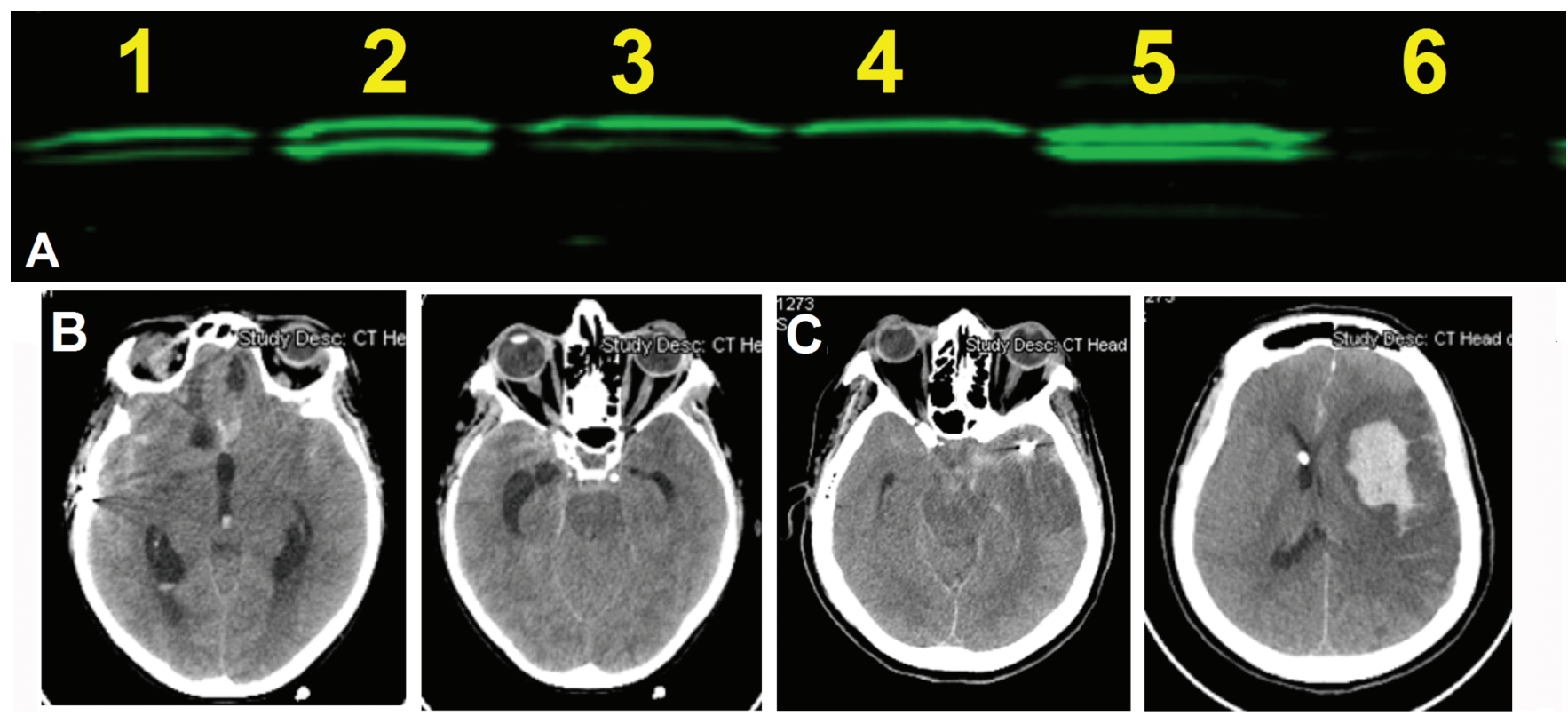

FIG. 1. A: Representative Western blot of HMGB1 in CSF samples collected from patients with aneurysmal SAH (lanes 1-5) and a control patient with NPH (lane 6). Blots were imaged using a Li-Cor Odyssey near-infrared imaging system. Patients with SAH consistently presented with an $\sim 25 \mathrm{kD}$ band corresponding to HMGB1, whereas patients with NPH did not show a clear band. B: Noncontrast axial CT scans of a 45-year-old woman with a Hunt and Hess grade of III and a Fisher grade of 4. The patient was sleepy and confused following a ruptured left posterior communicating artery aneurysm. The patient's HMGB1 sample is depicted in lane 2 (A). C: Noncontrast axial CT scans of a 77-year-old woman with a Hunt and Hess grade of IV and a Fisher grade of 4 . The patient was stuporous with significant right hemiparesis following a ruptured left middle cerebral aneurysm. The patient's HMGB1 sample is depicted in lane $5(\mathrm{~A})$.

The function or functions of HMGB1 following $\mathrm{SAH}$ remain completely unexplored; however, intracerebroventricular administration of HMGB1 induced the expression of proinflammatory mediators (such as IL-1 $\beta$, tumor necrosis factor- $\alpha$, and IL-6) within the rodent brain. ${ }^{3,76}$ The mechanisms whereby extracellular HMGB1 increases the expression of neuroinflammatory mediators remain unstudied, but activation of the receptor for advanced glycation end products, TLR2, and/ or TLR4 mediate the effects of HMGB1 in the periphery. $5,53,54,56,77,82,100,107,122$ Along these same lines, HMGB1 activated the proinflammatory transcription factor nuclear factor-kappa B via a TLR-dependent pathway in mouse macrophages and human kidney cells. ${ }^{82}$ Consistent with these reports, the acute expression of TLR4 within astrocytes and vascular endothelium correlated with increased nuclear factor-kappa B activation and neuroinflammation following SAH in rats. ${ }^{68,69}$ Because neuroinflammation is an important component of early brain injury and neurological demise after SAH, ${ }^{82,86,87,96}$, 98,101,104,114,120 HMGB1 may represent a clinically relevant, mechanistic link between acute injury and secondary neurovascular injury following $\mathrm{SAH}$.

In response to inflammatory mediators, such as those that are increased after $\mathrm{SAH}$, macrophages, ${ }^{11,19}$ natural killer cells, ${ }^{95}$ and myeloid dendritic cells ${ }^{65}$ actively secrete HMGB1. In this case, the detection of elevated HMGB1 levels within the CSF may signal an adaptive immune response to clear cellular debris and promote resolution following a cerebral hemorrhage. In contrast, HMGB1 is not actively secreted within the CNS, but it is passively released into the extracellular space and CSF by necrotic neurons following cerebral ischemia ${ }^{88}$ Consistent with these findings, recent data from our laboratory suggests that neuronal HMGB1 is specifically released within the cerebral cortex following hemorrhagic stroke in mice (C.H.A. and K.M.D., unpublished observation, 2009). Thus, neuronally derived HMGB1 may provide an early marker of neurological injury, which if therapeutically targeted, could attenuate early brain injury after SAH. Ongoing work in our laboratory is actively characterizing the contributions of both immune and neuronal cells toward the post-SAH release of HMGB1. This knowledge will undoubtedly improve our understanding of disease pathophysiology and may provide a marker of acute neuronal injury after SAH (and possibly other neurological injuries).

\section{Future Prospects, Challenges, and Direction of the Field}

Despite significant advances in neurosurgical approaches, improvements in patient diagnosis, and intense research efforts, the mortality and morbidity following SAH remain unchanged. ${ }^{93}$ The notion that neurological demise following SAH is solely caused by the development of delayed cerebral vasospasm was challenged by a number of recent preclinical and clinical reports, in- 

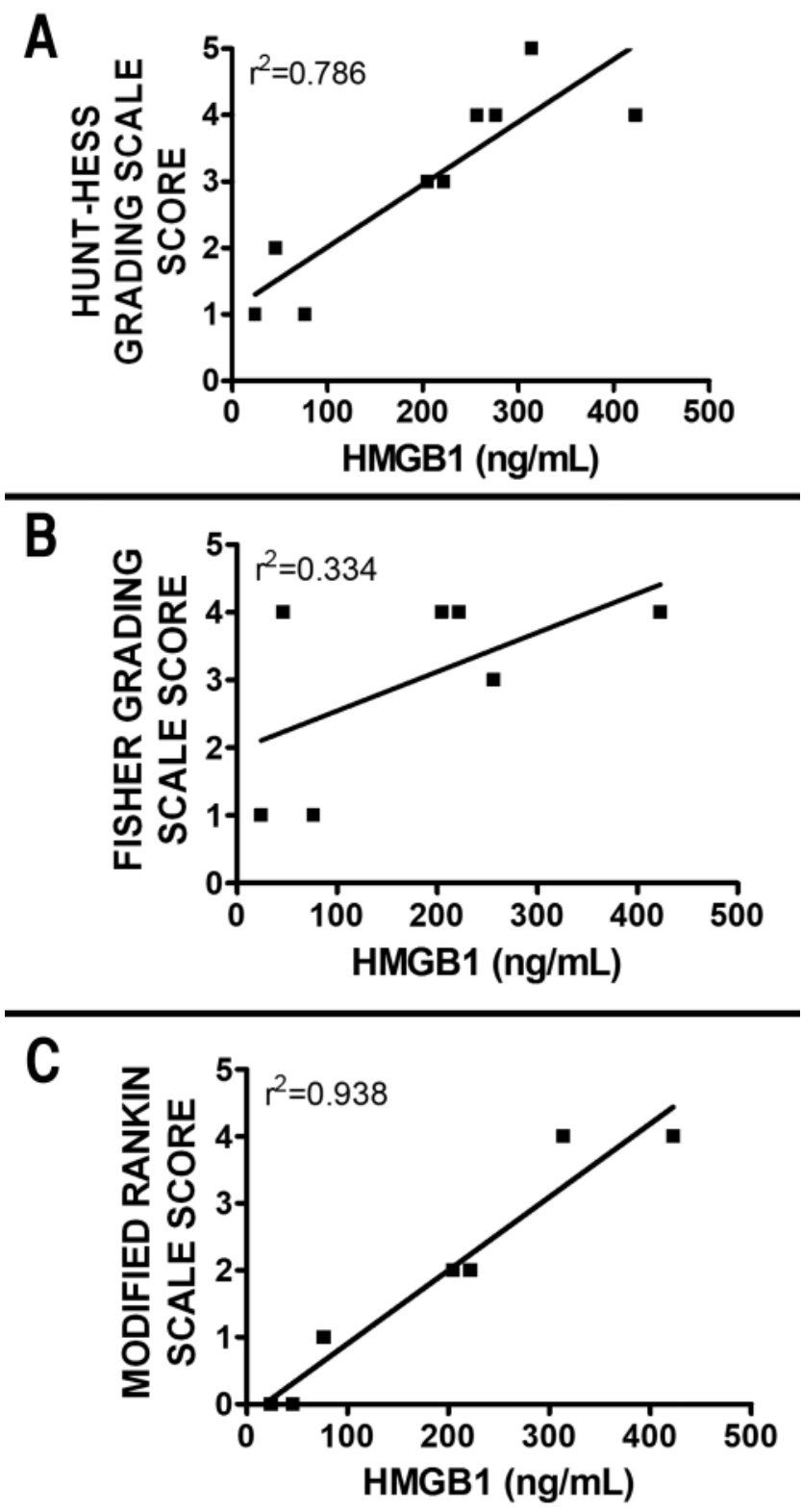

FIG. 2. Graphs of the retrospective correlation analysis of HMGB1 content within the CSF of patients with SAH according to the Hunt and Hess grade (A), Fisher grade (B), and modified Rankin scale score (C) at follow-up examination. High-mobility group box protein-1 was quantified by Western blotting. All grades were provided by the attending physician, who was blinded to experimental studies. High-mobility group box protein-1 was not present in the CSF of control patients with NPH.

cluding work by our laboratory, ${ }^{40,74,114}$ emphasizing the need for novel therapeutic targets and treatment modalities. Early brain injury is a primary cause of death in patients with $\mathrm{SAH}^{9,13}$ and emerged as a possible therapeutic target following SAH. Ongoing research suggests early brain injury involves complex neurovascular pathologies, including delayed cerebral ischemia, global edema, $\mathrm{BBB}$ disruption, cortical spreading depression, and neuroinflammation; ${ }^{16,79}$ however, the signaling pathways and mechanisms involved in the initiation of these events re- main largely unknown. Thus, innovative new approaches may be required to understand these complex processes.

Genomic and proteomic analyses are rapidly emerging as important tools for deciphering the complex neurovascular interactions in human physiology and disease. In particular, the incorporation of proteomics into the study of neurological diseases such as SAH may provide exciting new insights into the cellular mechanisms of brain injury. Unlike the retrospective study of individual genes/ proteins in postmortem patient specimens, neuroproteomics: 1) allows a sensitive and unbiased method to identify novel proteins associated with a given disease process (biomarkers); 2) can be used to identify novel proteins without the need for a specific hypothesis prior to experimentation; 3) is useful for analyzing patient samples, such as CSF and serum, which are collected in the routine care and treatment of patients on the neurosurgical unit; 4) can aid in deciphering complex cellular interactions, subcellular networks (synaptic function), and posttranslational modifications; 5) can support the development of large databases allowing the comparison of data between multiple medical centers; and 6) can be performed using equipment that is available at most major medical centers. Together, we believe these features of neuroproteomics will allow the widespread incorporation of this technology into clinical research and will provide important new insights regarding the mechanisms underlying $\mathrm{SAH}$ and other brain injuries.

\section{Disclosure}

This work was supported in part by grants to Dr. Dhandapani from the National Institutes of Health (No. NS065172) and American Heart Association (No. BGIA2300135) and by a fellowship received by Ms. Laird from the American Heart Association (No. PRE2250690).

Author contributions to the study and manuscript preparation include the following. Conception and design: KM Dhandapani, MD Laird, JR Vender, CH Alleyne. Acquisition of data: KM Dhandapani, MD Laird, SR Sangeetha, P Youssef, B Shakir, $\mathrm{CH}$ Alleyne. Analysis and interpretation of data: KM Dhandapani, MD King, MD Laird, SR Sangeetha, P Youssef, B Shakir. Drafting the article: KM Dhandapani, MD King, JR Vender, CH Alleyne. Critically revising the article: KM Dhandapani, MD King, JR Vender, CH Alleyne. Reviewed final version of manuscript and approved it for submission: KM Dhandapani, MD King, MD Laird, SR Sangeetha, B Shakir, JR Vender, $\mathrm{CH}$ Alleyne. Statistical analysis: KM Dhandapani, MD King, CH Alleyne. Study supervision: KM Dhandapani, JR Vender, $\mathrm{CH}$ Alleyne.

\section{References}

1. Abbott NJ, Revest PA, Romero IA: Astrocyte-endothelial interaction: physiology and pathology. Neuropathol Appl Neurobiol 18:424-433, 1992

2. Abdellah Z, Ahmadi A, Ahmed S, Aimable M, Ainscough R, Alemida $J$, et al: Finishing the euchromatic sequence of the human genome. Nature 431:931-945, 2004

3. Agnello D, Wang H, Yang H, Tracey KJ, Ghezzi P: HMGB-1, a DNA-binding protein with cytokine activity, induces brain TNF and IL- 6 production, and mediates anorexia and taste aversion. Cytokine 18:231-236, 2002

4. Andersson U, Wang H, Palmblad K, Aveberger AC, Bloom $\mathrm{O}$, Erlandsson-Harris $\mathrm{H}$, et al: High mobility group 1 protein 
(HMG-1) stimulates proinflammatory cytokine synthesis in human monocytes. J Exp Med 192:565-570, 2000

5. Apetoh L, Ghiringhelli F, Tesniere A, Criollo A, Ortiz C, Lidereau R, et al: The interaction between HMGB1 and TLR4 dictates the outcome of anticancer chemotherapy and radiotherapy. Immunol Rev 220:47-59, 2007

6. Ayer RE, Zhang JH: The clinical significance of acute brain injury in subarachnoid hemorrhage and opportunity for intervention. Acta Neurochir Suppl 105:179-184, 2008

7. Baird AE: Blood genomics in human stroke. Stroke 38 (2 Suppl):694-698, 2007

8. Bayés A, Grant SG: Neuroproteomics: understanding the molecular organization and complexity of the brain. Nat Rev Neurosci 10:635-646, 2009

9. Bederson JB, Levy AL, Ding WH, Kahn R, DiPerna CA, Jenkins AL III, et al: Acute vasoconstriction after subarachnoid hemorrhage. Neurosurgery 42:352-362, 1998

10. Biragyn A, Ruffini PA, Leifer CA, Klyushnenkova E, Shakhov A, Chertov O, et al: Toll-like receptor 4-dependent activation of dendritic cells by beta-defensin 2. Science 298:1025-1029, 2002

11. Bonaldi T, Talamo F, Scaffidi P, Ferrera D, Porto A, Bachi A, et al: Monocytic cells hyperacetylate chromatin protein HMGB1 to redirect it towards secretion. EMBO J 22:55515560,2003

12. Brawley BW, Strandness DE Jr, Kelly WA: The biphasic response of cerebral vasospasm in experimental subarachnoid hemorrhage. J Neurosurg 28:1-8, 1968

13. Broderick JP, Brott TG, Duldner JE, Tomsick T, Leach A: Initial and recurrent bleeding are the major causes of death following subarachnoid hemorrhage. Stroke 25:1342-1347, 1994

14. Burré J, Volknandt W: The synaptic vesicle proteome. J Neurochem 101:1448-1462, 2007

15. Bustin M: Regulation of DNA-dependent activities by the functional motifs of the high-mobility-group chromosomal proteins. Mol Cell Biol 19:5237-5246, 1999

16. Cahill J, Cahill WJ, Calvert JW, Calvert JH, Zhang JH: Mechanisms of early brain injury after subarachnoid hemorrhage. $\mathbf{J}$ Cereb Blood Flow Metab 26:1341-1353, 2006

17. Carboni L, Vighini M, Piubelli C, Castelletti L, Milli A, Domenici E: Proteomic analysis of rat hippocampus and frontal cortex after chronic treatment with fluoxetine or putative novel antidepressants: CRF1 and NK1 receptor antagonists. Eur Neuropsychopharmacol 16:521-537, 2006

18. Celis JE, Gromov P: High-resolution two-dimensional gel electrophoresis and protein identification using western blotting and ECL detection. EXS 88:55-67, 2000

19. Chen K, Lu J, Wang L, Gan YH: Mycobacterial heat shock protein 65 enhances antigen cross-presentation in dendritic cells independent of Toll-like receptor 4 signaling. J Leukoc Biol 75:260-266, 2004

20. Cheng AL, Hsu CH, Lin JK, Hsu MM, Ho YF, Shen TS, et al: Phase I clinical trial of curcumin, a chemopreventive agent, in patients with high-risk or pre-malignant lesions. Anticancer Res 21 (4B):2895-2900, 2001

21. Claassen J, Carhuapoma JR, Kreiter KT, Du EY, Connolly ES, Mayer SA: Global cerebral edema after subarachnoid hemorrhage: frequency, predictors, and impact on outcome. Stroke 33:1225-1232, 2002

22. Clower BR, Yamamoto Y, Cain L, Haines DE, Smith RR: Endothelial injury following experimental subarachnoid hemorrhage in rats: effects on brain blood flow. Anat Rec 240:104114, 1994

23. Correale J, Villa A: The neuroprotective role of inflammation in nervous system injuries. J Neurol 251:1304-1316, 2004

24. Delmotte P: Gel isoelectric focusing of cerebrospinal fluid proteins: a potential diagnostic tool. Z Klin Chem Klin Biochem 9:334-336, 1971
25. Dóczi T, Joó F, Adám G, Bozóky B, Szerdahelyi P: Bloodbrain barrier damage during the acute stage of subarachnoid hemorrhage, as exemplified by a new animal model. Neurosurgery 18:733-739, 1986

26. Dóczi T, Joó F, Sonkodi S, Adám G: Increased vulnerability of the blood-brain barrier to experimental subarachnoid hemorrhage in spontaneously hypertensive rats. Stroke 17:498-501, 1986

27. Dosemeci A, Tao-Cheng JH, Vinade L, Jaffe H: Preparation of postsynaptic density fraction from hippocampal slices and proteomic analysis. Biochem Biophys Res Commun 339: 687-694, 2006

28. Du X, Tang Y, Xu H, Lit L, Walker W, Ashwood P, et al: Genomic profiles for human peripheral blood $\mathrm{T}$ cells, B cells, natural killer cells, monocytes, and polymorphonuclear cells: comparisons to ischemic stroke, migraine, and Tourette syndrome. Genomics 87:693-703, 2006

29. Feigin VL, Lawes CM, Bennett DA, Anderson CS: Stroke epidemiology: a review of population-based studies of incidence, prevalence, and case-fatality in the late 20th century. Lancet Neurol 2:43-53, 2003

30. Felgenhauer K: Protein size and cerebrospinal fluid composition. Klin Wochenschr 52:1158-1164, 1974

31. Fossard C, Dale G, Latner AL: Separation of the proteins of cerebrospinal fluid using gel electrofocusing followed by electrophoresis. J Clin Pathol 23:586-589, 1970

32. Gaetani P, Tartara F, Pignatti P, Tancioni F, Rodriguez y Baena R, De Benedetti F: Cisternal CSF levels of cytokines after subarachnoid hemorrhage. Neurol Res 20:337-342, 1998

33. Germanò A, Caffo M, Angileri FF, Arcadi F, NewcombFernandez J, Caruso G, et al: NMDA receptor antagonist felbamate reduces behavioral deficits and blood-brain barrier permeability changes after experimental subarachnoid hemorrhage in the rat. J Neurotrauma 24:732-744, 2007

34. Germanò A, d'Avella D, Imperatore C, Caruso G, Tomasello F: Time-course of blood-brain barrier permeability changes after experimental subarachnoid haemorrhage. Acta Neurochir (Wien) 142:575-581, 2000

35. Goldman D, Merril CR, Ebert MH: Two-dimensional gel electrophoresis of cerebrospinal fluid proteins. Clin Chem 26:1317-1322, 1980

36. Goldstein RS, Gallowitsch-Puerta M, Yang L, Rosas-Ballina M, Huston JM, Czura CJ, et al: Elevated high-mobility group box 1 levels in patients with cerebral and myocardial ischemia. Shock 25:571-574, 2006

37. Gygi SP, Rochon Y, Franza BR, Aebersold R: Correlation between protein and mRNA abundance in yeast. Mol Cell Biol 19:1720-1730, 1999

38. Hackett ML, Anderson CS: Health outcomes 1 year after subarachnoid hemorrhage: an international population-based study. Neurology 55:658-662, 2000

39. Hadjivassiliou M, Tooth CL, Romanowski CA, Byrne J, Battersby RD, Oxbury S, et al: Aneurysmal SAH: cognitive outcome and structural damage after clipping or coiling. Neurology 56:1672-1677, 2001

40. Hansen-Schwartz J, Vajkoczy P, Macdonald RL, Pluta RM, Zhang JH: Cerebral vasospasm: looking beyond vasoconstriction. Trends Pharmacol Sci 28:252-256, 2007

41. Haskins WE, Kobeissy FH, Wolper RA, Ottens AK, Kitlen JW, McClung SH, et al: Rapid discovery of putative protein biomarkers of traumatic brain injury by SDS-PAGE-capillary liquid chromatography-tandem mass spectrometry. J Neurotrauma 22:629-644, 2005

42. Hendryk S, Jarzab B, Josko J: Increase of the IL-1 beta and IL-6 levels in CSF in patients with vasospasm following aneurysmal SAH. Neuroendocrinol Lett 25:141-147, 2004

43. Hohlfeld R, Kerschensteiner M, Stadelmann C, Lassmann H, Wekerle H: The neuroprotective effect of inflammation: im- 
plications for the therapy of multiple sclerosis. Ernst Schering Res Found Workshop 53:23-38, 2005

44. Hoozemans JJ, O'Banion MK: The role of COX-1 and COX-2 in Alzheimer's disease pathology and the therapeutic potentials of non-steroidal anti-inflammatory drugs. Curr Drug Targets CNS Neurol Disord 4:307-315, 2005

45. Hütter BO, Kreitschmann-Andermahr I, Mayfrank L, Rohde V, Spetzger U, Gilsbach JM: Functional outcome after aneurysmal subarachnoid hemorrhage. Acta Neurochir Suppl 72:157-174, 1999

46. Iadecola C, Niwa K, Nogawa S, Zhao X, Nagayama M, Araki $\mathrm{E}$, et al: Reduced susceptibility to ischemic brain injury and $\mathrm{N}$-methyl-D-aspartate-mediated neurotoxicity in cyclooxygenase-2-deficient mice. Proc Natl Acad Sci U S A 98:12941299, 2001

47. Janzer RC, Raff MC: Astrocytes induce blood-brain barrier properties in endothelial cells. Nature 325:253-257, 1987

48. Juvela S: Aspirin and delayed cerebral ischemia after aneurysmal subarachnoid hemorrhage. J Neurosurg 82:945-952, 1995

49. Kamii H, Kato I, Kinouchi H, Chan PH, Epstein CJ, Akabane A, et al: Amelioration of vasospasm after subarachnoid hemorrhage in transgenic mice overexpressing $\mathrm{CuZn}$-superoxide dismutase. Stroke 30:867-872, 1999

50. Kaynar MY, Tanriverdi T, Kemerdere R, Atukeren P, Gumustas K: Cerebrospinal fluid superoxide dismutase and serum malondialdehyde levels in patients with aneurysmal subarachnoid hemorrhage: preliminary results. Neurol Res 27: 562-567, 2005

51. Kjellin KG, Stibler H: Protein pattern or cerebrospinal fluid in spasmodic torticollis. J Neurol Neurosurg Psychiatry 37: 1128-1132, 1974

52. Klemmer P, Smit AB, Li KW: Proteomics analysis of immuno-precipitated synaptic protein complexes. J Proteomics 72:82-90, 2009

53. Klune JR, Dhupar R, Cardinal J, Billiar TR, Tsung A: HMGB1: endogenous danger signaling. Mol Med 14:476-484, 2008

54. Kokkola R, Andersson A, Mullins G, Ostberg T, Treutiger CJ, Arnold B, et al: RAGE is the major receptor for the proinflammatory activity of HMGB1 in rodent macrophages. Scand $\mathbf{J}$ Immunol 61:1-9, 2005

55. Kusaka G, Ishikawa M, Nanda A, Granger DN, Zhang JH: Signaling pathways for early brain injury after subarachnoid hemorrhage. J Cereb Blood Flow Metab 24:916-925, 2004

56. Lander ES, Linton LM, Birren B, Nusbaum C, Zody MC, Baldwin J, et al : Initial sequencing and analysis of the human genome. Nature 409:860-921, 2001

57. Landsman D, Bustin M: A signature for the HMG-1 box DNAbinding proteins. Bioessays 15:539-546, 1993

58. Lee JY, Sagher O, Keep R, Hua Y, Xi G: Comparison of experimental rat models of early brain injury after subarachnoid hemorrhage. Neurosurgery 65:331-343, 2009

59. Leonoudakis D, Conti LR, Anderson S, Radeke CM, McGuire LM, Adams ME, et al: Protein trafficking and anchoring complexes revealed by proteomic analysis of inward rectifier potassium channel (Kir2.x)-associated proteins. J Biol Chem 279:22331-22346, 2004

60. Liao SL, Chen WY, Raung SL, Kuo JS, Chen CJ: Association of immune responses and ischemic brain infarction in rat. Neuroreport 12:1943-1947, 2001

61. Liebenberg WA, Worth R, Firth GB, Olney J, Norris JS: Aneurysmal subarachnoid haemorrhage: guidance in making the correct diagnosis. Postgrad Med J 81:470-473, 2005

62. Linn FH, Rinkel GJ, Algra A, van Gijn J: Incidence of subarachnoid hemorrhage: role of region, year, and rate of computed tomography: a meta-analysis. Stroke 27:625-629, 1996

63. Liu SH, Cheng HH, Huang SY, Yiu PC, Chang YC: Studying the protein organization of the postsynaptic density by a novel solid phase- and chemical cross-linking-based technology. Mol Cell Proteomics 5:1019-1032, 2006

64. Longstreth WT Jr, Nelson LM, Koepsell TD, van Belle G: Clinical course of spontaneous subarachnoid hemorrhage: a population-based study in King County, Washington. Neurology 43:712-718, 1993

65. Lotze MT, Tracey KJ: High-mobility group box 1 protein (HMGB1): nuclear weapon in the immune arsenal. Nat Rev Immunol 5:331-342, 2005

66. Lovell MA, Xie C, Markesbery WR: Decreased glutathione transferase activity in brain and ventricular fluid in Alzheimer's disease. Neurology 51:1562-1566, 1998

67. Lukiw WJ, Bazan NG: Neuroinflammatory signaling upregulation in Alzheimer's disease. Neurochem Res 25:1173-1184, 2000

68. Ma CX, Yin WN, Cai BW, He M, Wu J, Wang JY, et al: Activation of TLR4/NF- $\kappa B$ signaling pathway in early brain injury after subarachnoid hemorrhage. Neurol Res [epub ahead of print], 2009

69. Ma CX, Yin WN, Cai BW, Wu J, Wang JY, He M, et al: Tolllike receptor 4/nuclear factor-kappa B signaling detected in brain after early subarachnoid hemorrhage. Chin Med J (Engl) 122:1575-1581, 2009

70. Macdonald RL, Pluta RM, Zhang JH: Cerebral vasospasm after subarachnoid hemorrhage: the emerging revolution. Nat Clin Pract Neurol 3:256-263, 2007

71. Mahesh VB, Dhandapani KM, Brann DW: Role of astrocytes in reproduction and neuroprotection. Mol Cell Endocrinol 246:1-9, 2006

72. McGirt MJ, Parra A, Sheng H, Higuchi Y, Oury TD, Laskowitz DT, et al: Attenuation of cerebral vasospasm after subarachnoid hemorrhage in mice overexpressing extracellular superoxide dismutase. Stroke 33:2317-2323, 2002

73. McGirt MJ, Woodworth GF, Pradilla G, Legnani F, Warner D, Tamargo R, et al: Galbraith Award: simvastatin attenuates experimental cerebral vasospasm and ameliorates serum markers of neuronal and endothelial injury in patients after subarachnoid hemorrhage: a dose-response effect dependent on endothelial nitric oxide synthase. Clin Neurosurg 52:371378,2005

74. Mesis RG, Wang H, Lombard FW, Yates R, Vitek MP, Borel $\mathrm{CO}$, et al: Dissociation between vasospasm and functional improvement in a murine model of subarachnoid hemorrhage. Neurosurg Focus 21(3):E4, 2006

75. Murata Y, Doi T, Taniguchi H, Fujiyoshi Y: Proteomic analysis revealed a novel synaptic proline-rich membrane protein (PRR7) associated with PSD-95 and NMDA receptor. Biochem Biophys Res Commun 327:183-191, 2005

76. O'Connor KA, Hansen MK, Rachal Pugh C, Deak MM, Biedenkapp JC, Milligan ED, et al: Further characterization of high mobility group box 1 (HMGB1) as a proinflammatory cytokine: central nervous system effects. Cytokine 24:254265,2003

77. Onda H, Kasuya H, Takakura K, Hori T, Imaizumi T, Takeuchi $\mathrm{T}$, et al: Identification of genes differentially expressed in canine vasospastic cerebral arteries after subarachnoid hemorrhage. J Cereb Blood Flow Metab 19:1279-1288, 1999

78. Ong SE, Mann M: Mass spectrometry-based proteomics turns quantitative. Nat Chem Biol 1:252-262, 2005

79. Ostrowski RP, Colohan AR, Zhang JH: Mechanisms of hyperbaric oxygen-induced neuroprotection in a rat model of subarachnoid hemorrhage. J Cereb Blood Flow Metab 25: 554-571, 2005

80. Pan S, Rush J, Peskind ER, Galasko D, Chung K, Quinn J, et al: Application of targeted quantitative proteomics analysis in human cerebrospinal fluid using a liquid chromatography matrix-assisted laser desorption/ionization time-of-flight tandem mass spectrometer (LC MALDI TOF/TOF) platform. J Proteome Res 7:720-730, 2008 
81. Pan S, Zhu D, Quinn JF, Peskind ER, Montine TJ, Lin B, et al: A combined dataset of human cerebrospinal fluid proteins identified by multi-dimensional chromatography and tandem mass spectrometry. Proteomics 7:469-473, 2007

82. Park S, Yamaguchi M, Zhou C, Calvert JW, Tang J, Zhang JH: Neurovascular protection reduces early brain injury after subarachnoid hemorrhage. Stroke 35:2412-2417, 2004

83. Pfrieger FW, Barres BA: Synaptic efficacy enhanced by glial cells in vitro. Science 277:1684-1687, 1997

84. Pluta RM, Hansen-Schwartz J, Dreier J, Vajkoczy P, Macdonald RL, Nishizawa $S$, et al: Cerebral vasospasm following subarachnoid hemorrhage: time for a new world of thought. Neurol Res 31:151-158, 2009

85. Pradilla G, Thai QA, Legnani FG, Clatterbuck RE, Gailloud P, Murphy KP, et al: Local delivery of ibuprofen via controlledrelease polymers prevents angiographic vasospasm in a monkey model of subarachnoid hemorrhage. Neurosurgery 57 (1 Suppl):184-190, 2005

86. Provencio JJ, Vora N: Subarachnoid hemorrhage and inflammation: bench to bedside and back. Semin Neurol 25:435-444, 2005

87. Prunell GF, Svendgaard NA, Alkass K, Mathiesen T: Delayed cell death related to acute cerebral blood flow changes following subarachnoid hemorrhage in the rat brain. J Neurosurg 102: 1046-1054, 2005

88. Qiu J, Nishimura M, Wang Y, Sims JR, Qiu S, Savitz SI, et al: Early release of HMGB-1 from neurons after the onset of brain ischemia. J Cereb Blood Flow Metab 28:927-938, 2008

89. Qureshi AI, Sung GY, Suri MA, Straw RN, Guterman LR, Hopkins LN: Prognostic value and determinants of ultraearly angiographic vasospasm after aneurysmal subarachnoid hemorrhage. Neurosurgery 44:967-974, 1999

90. Rodriguez y Baena R, Gaetani P, Silvani V, Viganò T, Crivellari MT, Paoletti P: Cisternal and lumbar CSF levels of arachidonate metabolites after subarachnoid haemorrhage: an assessment of the biochemical hypothesis of vasospasm. Acta Neurochir (Wien) 84:129-135, 1987

91. Roman RJ, Renic M, Dunn KM, Takeuchi K, Hacein-Bey L: Evidence that 20-HETE contributes to the development of acute and delayed cerebral vasospasm. Neurol Res 28:738-749, 2006

92. Saito A, Kamii H, Kato I, Takasawa S, Kondo T, Chan PH, et al: Transgenic CuZn-superoxide dismutase inhibits NO synthase induction in experimental subarachnoid hemorrhage. Stroke 32:1652-1657, 2001

93. Schievink WI, Riedinger M, Jhutty TK, Simon P: Racial disparities in subarachnoid hemorrhage mortality: Los Angeles County, California, 1985-1998. Neuroepidemiology 23: 299-305, 2004

94. Schrimpf SP, Meskenaite V, Brunner E, Rutishauser D, Walther $\mathrm{P}$, Eng J, et al: Proteomic analysis of synaptosomes using isotope-coded affinity tags and mass spectrometry. Proteomics 5:2531-2541, 2005

95. Semino C, Angelini G, Poggi A, Rubartelli A: NK/iDC interaction results in IL-18 secretion by DCs at the synaptic cleft followed by NK cell activation and release of the DC maturation factor HMGB1. Blood 106:609-616, 2005

96. Sercombe R, Dinh YR, Gomis P: Cerebrovascular inflammation following subarachnoid hemorrhage. Jpn J Pharmacol 88:227-249, 2002

97. Shigeno T, Fritschka E, Brock M, Schramm J, Shigeno S, Cervoś-Navarro J: Cerebral edema following experimental subarachnoid hemorrhage. Stroke 13:368-379, 1982

98. Simard JM, Geng Z, Woo SK, Ivanova S, Tosun C, Melnichenko $\mathrm{L}$, et al: Glibenclamide reduces inflammation, vasogenic edema, and caspase-3 activation after subarachnoid hemorrhage. J Cereb Blood Flow Metab 29:317-330, 2009

99. Sitia G, Iannacone M, Müller S, Bianchi ME, Guidotti LG: Treatment with HMGB1 inhibitors diminishes CTL-induced liver disease in HBV transgenic mice. J Leukoc Biol 81:100107, 2007

100. Sorci G, Riuzzi F, Arcuri C, Giambanco I, Donato R: Amphoterin stimulates myogenesis and counteracts the antimyogenic factors basic fibroblast growth factor and S100B via RAGE binding. Mol Cell Biol 24:4880-4894, 2004

101. Sozen T, Tsuchiyama R, Hasegawa Y, Suzuki H, Jadhav V, Nishizawa S, et al: Role of interleukin-1beta in early brain injury after subarachnoid hemorrhage in mice. Stroke 40:2519-2525, 2009

102. Takamori S, Holt M, Stenius K, Lemke EA, Grønborg M, Riedel D, et al: Molecular anatomy of a trafficking organelle. Cell 127:831-846, 2006

103. Takano T, Tian GF, Peng W, Lou N, Libionka W, Han X, et al: Astrocyte-mediated control of cerebral blood flow. Nat Neurosci 9:260-267, 2006

104. Takizawa T, Tada T, Kitazawa K, Tanaka Y, Hongo K, Kameko $\mathrm{M}$, et al: Inflammatory cytokine cascade released by leukocytes in cerebrospinal fluid after subarachnoid hemorrhage. Neurol Res 23:724-730, 2001

105. Tang SC, Arumugam TV, Xu X, Cheng A, Mughal MR, Jo DG, et al: Pivotal role for neuronal Toll-like receptors in ischemic brain injury and functional deficits. Proc Natl Acad Sci U S A 104:13798-13803, 2007

106. Thomas JO, Travers AA: HMG1 and 2, and related 'architectural' DNA-binding proteins. Trends Biochem Sci 26:167-174, 2001

107. Tsung A, Klune JR, Zhang X, Jeyabalan G, Cao Z, Peng X, et al: HMGB1 release induced by liver ischemia involves Toll-like receptor 4 dependent reactive oxygen species production and calcium-mediated signaling. J Exp Med 204:2913-2923, 2007

108. Ullian EM, Christopherson KS, Barres BA: Role for glia in synaptogenesis. Glia 47:209-216, 2004

109. Ullian EM, Sapperstein SK, Christopherson KS, Barres BA: Control of synapse number by glia. Science 291:657-661, 2001

110. Van Elzen R, Moens L, Dewilde S: Expression profiling of the cerebral ischemic and hypoxic response. Expert Rev Proteomics 5:263-282, 2008

111. van Gijn J, Rinkel GJ: Subarachnoid haemorrhage: diagnosis, causes and management. Brain 124:249-278, 2001

112. Vikman P, Beg S, Khurana TS, Khurana T, Hansen-Schwartz $\mathrm{J}$, Edvinsson L: Gene expression and molecular changes in cerebral arteries following subarachnoid hemorrhage in the rat. $\mathbf{J}$ Neurosurg 105:438-444, 2006

113. von Baumgarten L, Trabold R, Thal S, Back T, Plesnila N: Role of cortical spreading depressions for secondary brain damage after traumatic brain injury in mice. J Cereb Blood Flow Metab 28:1353-1360, 2008

114. Wakade C, King MD, Laird MD, Alleyne CH Jr, Dhandapani KM: Curcumin attenuates vascular inflammation and cerebral vasospasm after subarachnoid hemorrhage in mice. Antioxid Redox Signal 11:35-45, 2009

115. Wang KK, Ottens AK, Liu MC, Lewis SB, Meegan C, Oli MW, et al: Proteomic identification of biomarkers of traumatic brain injury. Expert Rev Proteomics 2:603-614, 2005

116. White RP, Robertson JT: Comparison of piroxicam, meclofenamate, ibuprofen, aspirin, and prostacyclin efficacy in a chronic model of cerebral vasospasm. Neurosurgery 12:40-46, 1983

117. Whittle IR, Short DM, Deighton RF, Kerr LE, Smith C, McCulloch J: Proteomic analysis of gliomas. Br J Neurosurg 21:576-582, 2007

118. Wilkins RH: Aneurysm rupture during angiography: does acute vasospasm occur? Surg Neurol 5:299-303, 1976

119. Yatsushige H, Ostrowski RP, Tsubokawa T, Colohan A, Zhang JH: Role of c-Jun N-terminal kinase in early brain injury after subarachnoid hemorrhage. J Neurosci Res 85:1436-1448, 2007

120. Yoshimoto Y, Tanaka Y, Hoya K: Acute systemic inflamma- 
M. D. King et al.

tory response syndrome in subarachnoid hemorrhage. Stroke 32:1989-1993, 2001

121. Yun M, Wu W, Hood L, Harrington M: Human cerebrospinal fluid protein database: edition 1992. Electrophoresis 13:10021013,1992

122. Zhou ML, Wu W, Ding YS, Zhang FF, Hang CH, Wang HD, et al: Expression of Toll-like receptor 4 in the basilar artery after experimental subarachnoid hemorrhage in rabbits: a preliminary study. Brain Res 1173:110-116, 2007

123. Zubkov AY, Ogihara K, Bernanke DH, Parent AD, Zhang J: Apoptosis of endothelial cells in vessels affected by cerebral vasospasm. Surg Neurol 53:260-266, 2000

124. Zubkov AY, Tibbs RE, Clower B, Ogihara K, Aoki K, Zhang $\mathrm{JH}$ : Apoptosis in basilar endothelial cells in a canine double hemorrhage model. Acta Neurochir Suppl 77:29-31, 2001
125. Zubkov AY, Tibbs RE, Clower B, Ogihara K, Aoki K, Zhang $\mathrm{JH}$ : Morphological changes of cerebral arteries in a canine double hemorrhage model. Neurosci Lett 326:137-141, 2002

Manuscript submitted September 24, 2009

Accepted October 21, 2009.

Address correspondence to: Krishnan M. Dhandapani, Ph.D., Department of Neurosurgery, BI-3088, Medical College of Georgia, Augusta, Georgia 30809. email: kdhandapani@mcg.edu. 